\title{
VEINTICINCO AÑOS DE FUNCIÓN CONSULTIVA
}

\author{
VICENTE GARRIDO MAYOL \\ Presidente del Consejo Consultivo de la Generalitat Valenciana. \\ Profesor Titular de Derecho Constitucional \\ Universitat de Valencia
}




\section{SUMARIO}

I. INTRODUCCIÓN. II. LA JUSTIFICACIÓN DE LA FUNCIÓN CONSULTIVA. III. LA FUNCIÓN CONSULTIVA EN ESPAÑA: DEL MONOPOLIO A LA DIVERSIDAD. IV. TIPOLOGÍA DE los órganos consultivos. V. El extraño modelo del País Vasco. VI. RecaPITULACIÓN. 


\title{
VEINTICINCO AÑOS DE FUNCIÓN CONSULTIVA
}

\author{
POR \\ VICENTE GARRIDO MAYOL \\ Presidente del Consejo Consultivo de la Generalitat Valenciana. \\ ProfesorTitular de Derecho Constitucional \\ Universitat de Valencia
}

\section{INTRODUCCIÓN}

El Título IV de la Constitución, dedicado a la regulación del Gobierno y de la Administración, incluye el art. 107 que prescribe que "El Consejo de Estado es el supremo órgano consultivo del Gobierno. Una Ley Orgánica regulará su composición y competencia».

El constituyente de 1978 quiso, de esta forma, otorgar relevancia constitucional a un órgano de gran tradición en España y que durante siglos ha ejercido el monopolio de la función consultiva1.

Hay quien ha señalado que el precedente remoto del Consejo de Estado es el Consejo Real de Castilla. Otros, que sucede al creado por Carlos V en $1526^{2}$, como organismo central de la Monarquía y supremo órgano asesor del Monarca, que era su Presidente.

1 Actualmente son múltiples los órganos consultivos en distintos ámbitos y materias: económico-social, cultural, científico y tecnológico, etc... Sin embargo, la "función consultiva» por antonomasia se identifica con la que ha venido ejerciendo el Consejo de Estado, como eficaz garantía para el interés general y la legalidad, procurando el acierto y, en su caso, la oportunidad, en la toma de decisiones por parte del Gobierno. Función consultiva cuyo ejercicio comparten hoy los respectivos Consejos Consultivos de la Comunidades Autónomas.

2 Vid. E. García-Trevijano Fos, Tratado de Derecho Administrativo, tomo II, Ed. Revista Derecho Privado, Madrid, 1971, págs. 648 y ss.; F. BARRIOS, El Consejo 
En la etapa constitucional, ya el Estatuto de Bayona contenía previsiones al respecto configurando un Consejo de Estado muy influido por el Consejo de Estado napoleónico. En la Constitución de 1812 se estableció un Consejo del Rey para asesorar en los asuntos graves de gobierno como órgano independiente de los tres poderes clásicos. En 1845 se creó un "Consejo Real" como elemento indispensable del gobierno constitucional, "para que el gobierno marche de un modo ordenado, pero también para poner obstáculos a los trastornos políticos; porque la causa constante que los produce, cualquiera que sean las ocasiones que los desarrollen, son los excesos del poder y el Consejo Real sirve precisamente para tenerlo a raya” ${ }^{3}$ Se le reconoció máximo rango, después del Consejo de Ministros.

Una Ley de 1860 configuró al Consejo de Estado como Cuerpo Consultivo del Gobierno reconociéndole funciones jurisdiccionales contencioso-administrativas, de las que fue privado por Ley de 1904 que las trasladó al Tribunal Supremo. Aunque las Constituciones de 1869 y de 1876 no se ocuparon de regular el Consejo, daban por supuesto su existencia en numerosos artículos.

La Constitución Republicana de 1931 preveía un "Cuerpo Consultivo Supremo de la República, en asuntos de gobierno y administración». Precisamente, un Decreto de 22 de abril del mismo año había disuelto el Pleno del Consejo - habida cuenta su composición-, y reorganizó la Comisión Permanente.

En 1940 se restableció el Consejo hasta que por Ley de 25 de noviembre de 1944 se aprobó el nuevo Estatuto Orgánico del Consejo de Estado, dándole una configuración que se asemeja a la actual, regulada por Ley Orgánica 3/1980, promulgada en desarrollo de las previsiones de la Constitución de 19784 .

de Estado de la Monarquía Española: 1521-1812, editado por el Consejo de Estado, Madrid, 1984, págs. 31 y ss.

3 Cfr. A. NiETo, «Del Consejo Real como elemento del Gobierno Constitucional", Revista Española de Administración Pública, n. ${ }^{\circ} 84$, septiembre-diciembre de 1977.

4 Sobre la historia y evolución del Consejo de Estado, puede consultarse, entre otros, F. BARrIOS, El Consejo de Estado de la Monarquía Constitucional, cit.; L. JoRDANA DE POZAS, "El Consejo de Estado (1944-1970)", Revista de Administración Pública, n. ${ }^{\circ}$ 64, enero-abril de 1971; J. M. MARTiN OVIEDO, "Treinta años de la Ley Orgánica del Consejo de Estado. Panorama de normas en relación con el mismo", Revista de Administración Pública, n. ${ }^{\circ} 75$, septiembre a diciembre de 1974; C. Rulz Miguel, Consejo de Estado y Consejos Consultivos Autonómicos, Dykinson, 1995, págs. 23 y ss. 
Lo anteriormente indicado pone de manifiesto que la función Consultiva goza de gran tradición en España y que ha sido ejercida por un Órgano que, aun con diferentes competencias y variable composición, se ha ganado, por su solvencia técnica y su independencia de criterio, un merecido prestigio en su fundamental papel de asesoramiento al Gobierno en asuntos de especial importancia.

Hoy, la función consultiva es ejercida, además de por el Consejo de Estado, por los Consejos Consultivos de la practica totalidad de las Comunidades Autónomas que han creado sus propios órganos a tal fin. El ejercicio de la función consultiva ha experimentado, por tanto, una profunda transformación durante el período de vigencia de la Constitución de 1978, que homenajeamos en su vigésimo quinto aniversario.

\section{LA JUSTIFICACIÓN DE LA FUNCIÓN CONSULTIVA}

Como es sabido, el Estado de Derecho se configura modernamente como un ente garantizador de los derechos de los ciudadanos. Todas las notas que lo caracterizan cumplen la función de preservarlos y de proteger al ciudadano -elemento central del sistema-, frente a los ataques o abusos que pueda sufrir, especialmente, por parte de los poderes públicos.

La aplicación de la teoría de la división de poderes trata de evitar una concentración excesiva de poder en unas mismas manos y de posibilitar mutuos y recíprocos controles entre los órganos del Estado que ejercen potestades públicas, para evitar situaciones de inobservancia de la ley o de abuso, a las que la propia naturaleza humana suele abocar.

El reconocimiento de los derechos y libertades tiene escasa trascendencia si no va acompañado de un sistema de garantías que permita un ejercicio real y efectivo de aquellos, con tajantes sanciones, en caso contrario, a quien obstaculice o impida su disfrute.

Y el sometimiento de los poderes públicos al Derecho los sitúa en la misma posición que los ciudadanos, a quienes se exige una adecuación de sus conductas al ordenamiento jurídico.

De ahí que los actos de la Administración Pública estén sometidos a control jurisdiccional, con la posibilidad de que puedan ser declarados nulos si materialmente son contrarios a Derecho o si se han producido inobservando el ordenamiento jurídico y generado indefensión con consecuencias no queridas por el administrado. 
En este ámbito de las garantías destaca la función consultiva, que comporta una garantia muy especial, no sólo para el administrado, sino, además, para el interés general, desarrollándose, fundamentalmente, dentro de estrictos parámetros jurídicos y contribuyendo con una consolidada doctrina legal a perfeccionar el sistema de garantías del Estado de Derecho.

Y consiste, en pocas palabras, en que un órgano ajeno a la Administración activa, independiente del Gobierno, e integrado por profesionales de reconocida solvencia, aconseje a aquel en relación con determinados asuntos de especial relevancia, con la pretensión de que su actuación sea acertada y ajustada a Derecho.Y es que el fundamento tradicional de la Administración consultiva se basa en la ajeneidad respecto a la toma de decisión: un órgano es el que resuelve, el que decide; $y$ otro órgano diferente es quien asesora con carácter previo, con la independencia de criterio que deriva de no estar sometido a relación jerárquica respecto al decisor. Objetividad técnica y separación respecto a la acción administrativa directa son, por tanto, dos notas fundamentales que deben caracterizar a los órganos consultivos ${ }^{5}$.

Por eso, es cierto que, como se ha destacado ${ }^{6}$ la credibilidad e importancia de todo órgano consultivo es directamente proporcional a su independencia y autonomía. Cuando ésta falta, el órgano consultivo se desnaturaliza y se dirige a justificar las actuaciones de la Administración activa.

En definitiva, tal y como ha sostenido el Tribunal Constitucional en su Sentencia 204/92, de capital importancia en relación con la función consultiva, "la intervención preceptiva de un órgano consultivo.., sea o no vinculante, supone en determinados casos una importantísima garantía del interés general y de la legalidad objetiva y, a consecuencia de ello, de los derechos y legítimos intereses de quienes son parte de un determinado procedimiento administrativo"?.

5 Vid. J. Balza Agullera, «Tendencias de la Administración Consultiva", R.V.A.P. n. 41 (1995), pág. 16.

6 Vid. E. Garcia-Trevijano Garnica, "Efectos de la omisión del preceptivo dictamen del Consejo de Estado", Revista de Administración Pública, n. ${ }^{\circ} 118$, pág. 257.

7 Fundamento Jurídico Cuarto.

Sobre derechos e intereses legítimos de los ciudadanos e interés general, vid. R. GómEz-FerRer Morant, "El Consejo de Estado y los derechos e intereses legítimos de los particulares", Documentación Administrativa, n. 244-245. I.N.A.P., Madrid, 1996, págs. 211 y ss. 
Pero, ¿es necesaria, en un Estado de Derecho, la función consultiva? ¿Son imprescindibles los órganos que la ejercen? ¿Por qué nuestra Carta Magna constitucionaliza el Consejo de Estado? ¿Por qué se han creado consejos consultivos autonómicos?

Ya expresé en otra ocasión ${ }^{8}$ que, a mi juicio, el Consejo de Estado no ejerce funciones ineludibles para la vitalidad del Estado. Dicho de otro modo, no es un órgano de naturaleza constitucional indispensable para el Estado, como puedan serlo las Cortes Generales, que ejercen la función legislativa, los Jueces y Tribunales, que tienen encomendada la administración de la justicia, o el Gobierno, titular de la función ejecutiva. No se concibe un Estado sin Parlamento, sin Gobierno o sin magistrados, pero no se compadecería si no existiera un órgano que ejerciera la función consultiva. El Consejo de Estado es, por tanto, un órgano de relevancia constitucional ${ }^{9}$, aunque de derecho necesario en nuestro sistema, habida cuenta que el legislador constituyente lo configuró como supremo órgano consultivo del Gobierno y dejó establecido el mandato de que una ley orgánica regulase su composición y competencia. $Y$ otro tanto cabe decir respecto de los consejos consultivos autonómicos en relación con las Comunidades Autónomas: no es consustancial al régimen de autonomía la existencia de órganos que ejerzan la función consultiva ${ }^{10}$, ni se prevé en la mayoría de los Estatutos de Autonomía la creación de los mismos, con lo cual, en la mayor parte de los casos, ni siquiera estamos ante Instituciones de derecho necesario.

Pero, como se ha visto, la función consultiva en España goza de una probada tradición, y viene avalada por la trayectoria impecable del

8 Vid. V. GARRIDO MAYOL, "La función consultiva en el sistema constitucional español: Consejo de Estado y Consejos consultivos autonómicos", en la obra colectiva Reflexiones sobre el XX Aniversario de la Constitución Española de 1978, I.N.A.P., Madrid, 1998, págs. 917 y ss.

9 Vid. J. Arozamena SierRa, "La caracterización constitucional del Consejo de Estado", Actualidad Administrativa, n. ${ }^{\circ}$ 244-245, I.N.A.P., Madrid, 1996, pág. 156. La Sentencia delTribunal Constitucional $59 / 90$ declaró que el Consejo de Estado tiene uen realidad el carácter de órgano del Estado con relevancia constitucional al servicio de la concepción de Estado que la propia Constitución establece...».

10 La consultiva no es una función básica, característica de la autonomía política. Sin embargo, no tiene mucho sentido que en relación con las Comunidades Autónomas, deba ser ejercida por un órgano de relevancia constitucional -inicialmente concebido para prestar su colaboración al Gobierno del Estado y a su Administración - , a no ser que sea porque las propias Comunidades así lo deseen, prefiriendo consultar al Consejo de Estado antes que crear un órgano consultivo propio. 
Consejo de Estado a lo largo de su historia. En el ejercicio de sus funciones, este órgano, que ha sobrevivido con muy distintos regímenes políticos, ha desempeñado un papel capital en el asesoramiento al Gobierno en asuntos de Estado y en la defensa del interés público y de los derechos individuales de los ciudadanos. Por ello está plenamente justificada la expresa mención al Consejo que contiene la Constitución, y la relevancia que ha adquirido hoy en día en España la función consultiva, sobre todo teniendo en cuenta la realidad de los Consejos Consultivos autonómicos que cumplen en las Comunidades Autónomas un papel similar al del Consejo de Estado, en su respectivo ámbito territorial.

Al Consejo de Estado y a los Consejos Consultivos autonómicos compete velar por la observancia del ordenamiento jurídico desde fuera de la Administración activa, mediante la emisión de dictámenes sobre pretensiones de la Administración "antes" de que se produzcan, pues no hay que olvidar que la intervención de los órganos consultivos es el último trámite del procedimiento administrativo inmediatamente anterior a la resolución del expediente o a la adopción del acuerdo que corresponda en los casos determinados por la ley. De ahí que los Consejos Consultivos se configuren como órganos colaboradores de la Administración en la conformación a Derecho de todas sus actuaciones en asuntos de preceptiva consulta. Una colaboración que se presta desde la independencia y la objetividad que los caracteriza, teniendo en cuenta su especial naturaleza y el estatuto jurídico de sus respectivos miembros. Mas que órganos de control, como a algunos les gusta considerarlos, estimo que lo son de cooperación necesaria, de prevención de la actividad de la Administración que ha de resultar conforme a Derecho, y que puede, por tanto, corregir por si misma, la propuesta de resolución que se somete a consideración de los Consejos Consultivos, en aquellos supuestos en que, aún sin estar obligada a ello - habida cuenta el carácter no vinculante del dictamen-, considere la razonabilidad y acierto del criterio del órgano consultado. Por ello, el trabajo que desarrollan los órganos que tienen encomendado el ejercicio de la función jurídico-consultiva, ha de ser eficaz - rapidez en la respuesta y calidad de su dictamen -, y no debe consistir en poner trabas innecesarias sino en buscar soluciones que se adecuen al ordenamiento jurídico.

En consecuencia, la función consultiva es un mecanismo que trata de garantizar los derechos del administrado y de preservar el interés público antes de que el acto administrativo se produzca, contrariamente a la función judicial que se ejerce «después» de que aquel se haya producido, controlando y corrigiendo, en su caso, la decisión de 
la Administración. Ambas funciones forman parte de ese, cada vez mas completo, sistema de garantías propio de un Estado de Derecho. Para ello, también es propio de la función consultiva auxiliar al Gobierno proporcionándole interpretaciones jurídicas estables" ${ }^{11}$, que marquen una senda que lleve al máximo acierto en la adopción de sus resoluciones.

Lo anteriormente expuesto justifica, a mi juicio, la bondad de la función consultiva ejercida hoy, además de por el Consejo de Estado, por los respectivos Consejos autonómicos.

\section{LA FUNCIÓN CONSULTIVA EN ESPAÑA: DEL MONOPOLIO A LA DIVERSIDAD}

En nuestra historia constitucional el Consejo de Estado ha ejercido de forma exclusiva lo que conocemos como función consultiva. La Constitución de 1978, posibilita la configuración de un Estado políticamente descentralizado y permite que las Comunidades Autónomas cuenten con sus propias Instituciones de autogobierno. En el proceso de construcción de nuestro Estado Autonómico ha sido evidente, y ello, en mi opinión, no es criticable, el mimetismo de las Comunidades Autónomas con respecto al Estado, al momento de organizar y determinar sus instituciones.

Aunque el art. 107 de la Constitución se refiere al Consejo de Estado como el supremo órgano consultivo del Gobierno, la Ley Orgánica $3 / 1980^{12}$ que lo regula lo faculta para "aconsejan también a las Comunidades Autónomas, que deberán recabar preceptivamente su dictamen en los mismos casos en que debe pedirlo el Estado, y cuando hayan asumido las competencias correspondientes.

$Y$ es que, tal y como ha declarado el Tribunal Constitucional -Sentencia 56/1990-, "El Consejo de Estado, pese a la dicción literal del artículo 107 de la Constitución Española... tiene en realidad carácter de órgano del Estado con relevancia constitucional al servicio de la concepción de Estado que la propia Constitución establece. Así resulta de su composición y de sus funciones consultivas, que se extienden también a las Comunidades Autónomas, según prevén explícita-

11 Vid. G. García Álvarez, La función constitucional del Consejo de Estado, CEDES, Barcelona, 1996, pág. 31.

12 Art. 23. 
mente, en el diseño competencial a que se remite la Norma Fundamental, los artículos 20 a 23 de Ley Orgánica del Consejo de Estado". $Y$ aclara el Alto Tribunal que "el concepto de Estado posee una naturaleza equívoca, por cuanto que puede usarse en diversos sentidos $y_{\text {, }}$ en concreto, bien como equivalente al conjunto de los poderes públicos, bien limitándose al conjunto de las instituciones centrales, o de ámbito nacional, en oposición a las Comunidades Autónomas".

De esta forma, como ha destacado López Menudo ${ }^{13}$ la Ley Orgánica del Consejo de Estado acogió una interpretación mucho más amplia de lo que, a la luz de la Constitución se presumia que podría ser el ámbito del Consejo de Estado. Interpretación que fue ratificada posteriormente, como se ha visto, por el Tribunal Constitucional ${ }^{14}$.

Ahora bien, el Tribunal Constitucional, en su Sentencia 204/1992 - de obligada cita para comprender que la función consultiva no es exclusiva del Estado concebido en sentido estricto-, afirmó que "ningún precepto constitucional y menos aún el que se refiere al Consejo de Estado, impide que, en el ejercicio de la autonomía organizativa, las Comunidades Autónomas puedan establecer en su propio ámbito, órganos consultivos equivalentes al Consejo de Estado en cuanto a su organización y competencias, siempre que éstas se ciñan a la esfera de atribuciones y actividades de los respectivos gobiernos y administraciones autonómicas».

Tal criterio es lógico y coherente con la nueva estructura territorial del Estado, en la que el ejercicio del poder político se halla repartido entre aquel y las Comunidades Autónomas. Si la función consultiva actúa como garantía de interés público y de la legalidad nada impide que dicha garantía pueda prestarse desde las Comunidades Autónomas. Como ha señalado Bravo-Ferrer, el Estado, al amparo de lo dispuesto en el art. 149-1-18. ${ }^{2}$ de la Constitución, puede imponer la garantía, pero no al garante ${ }^{15}$. Pero eso sí, el garante ha de estar reves-

13 F. LóPEZ MENUdo, "Presente y futuro competencial del Consejo de Estado y de los Consejos Consultivos autonómicos", en Constitución y el nuevo diseño de las Administraciones estatal $y$ autonómica, XIX Jornadas de Estudio de la Dirección del Sérvicio Jurídico del Estado. Ministerio de Justicia, Madrid, 1996, pág. 674.

14 Sobre esta cuestión vid. V. GARRIDO MAYOL, "La función consultiva en el sistema constitucional español: Consejo de Estado y Consejos Consultivos autonómicos", cit.

15 M. Bravo-Ferrer Delgado, "Consejo de Estado y Estado de autonomias", Revista Española de Derecho Administrativo, n. ${ }^{\circ} 60$, pág. 584. 
tido, como más adelante veremos, de similares rasgos a los que caracterizan al Consejo de Estado.

Por ello es lógico también, que elTribunal Constitucional indicara que en donde o en tanto semejantes órganos consultivos autonómicos, dotados de las características de organización y funcionamiento que aseguren su independencia, objetividad y rigurosa cualificación técnica, no existan, es decir, en aquellas Comunidades Autónomas que no cuenten con esta especialidad derivada de su organización propia, la garantía que representa la función consultiva "exige mantener la intervención preceptiva del Consejo de Estado".

Inicialmente, fueron pocos los Estatutos de Autonomía que preveían la existencia de un órgano que ejerciera la función consultiva. Sólo los de Cataluña, Canarias y Extremadura contemplaban Instituciones con competencias similares a las del Consejo de Estado.

Cataluña y Canarias crearon en 1981 y 1984, respectivamente, sus correspondientes Consejo Consultivos ${ }^{16}$. Pero fue tras la Sentencia del Tribunal Constitucional 204/1992 cuando la mayor parte de las Comunidades Autónomas crearon por Ley ${ }^{17}$, aún sin que sus Estatutos contuvieran previsión alguna al respecto, sus correspondientes órganos consultivos ${ }^{18}$.

En la actualidad, casi todos los Estatutos de Autonomía, prevén órganos consultivos ${ }^{19}, y$ con la excepción de Madrid, todas las Comu-

16 Cataluña, aparte del Consejo Consultivo, creó en 1985 la Comisión Jurídica Asesora, que ejerce la función consultiva en relación con expedientes administrativos sobre las materias que su propia Ley de creación determina, reservando al Consejo Consultivo el examen de la adecuación al Estatuto de autonomía de todos los proyectos y proposiciones de ley en la forma prevista en la ley que lo regula.

17 Blanouer Criado opina que los órganos consultivos autonómicos deben estar previstos en los correspondientes Estatutos de autonomía. Vid. en Consejo de Estado y autonomía, Ed.Tecnos, Madrid, 1994, págs. 62 y ss.

18 En 1993 fueron creados los Consejos Consultivos de las Islas Baleares y de Andalucía; un año después, el Consejo Jurídico Consultivo de la Comunidad Valenciana; en 1995, la Comisión Jurídica Asesora del Gobierno de Aragón, y los Consejos Consultivos de La Rioja, Galicia y Castilla-La Mancha; en 1997, fue creado el Consejo Jurídico de Murcia; en 1998, el de Cantabria; en 1999, el Consejo de Navarra y la Comisión Jurídico Asesora del País Vasco; en 2001, el Consejo Consultivo de Extremadura; y en 2002, el de Castilla y León.

19 Un total de once Estatutos de autonomía se reformaron entre 1996 y 1999, como consecuencia de los Pactos Autonómicos de 1992 con el objetivo fundamental de incrementar las competencias de las respectivas Comunidades autó- 
nidades Autónomas han creado su Consejo Consultivo, aunque en algunos casos como los de Extremadura, Asturias y Cantabria, aquellos aún no se han constituido.

Madrid es la única Comunidad Autónoma en la que ni estatutariamente ni legalmente está previsto un órgano consultivo, pues como se ha expuesto, las Comunidades que aún no lo han creado, sí que lo incluyen entre sus Instituciones de Gobierno. Todas las demás Comunidades Autónomas cuentan con sus respectivos Consejos Consultivos.

\section{TIPOLOGÍA DE LOS ÓRGANOS CONSULTIVOS}

ElTribunal Constitucional en su ya citada Sentencia 204/92 expresó que los órganos autonómicos a los que se podía encomendar el ejercicio de la función consultiva debían participar de las mismas características y tener idénticas o semejantes funciones a las del Consejo de Estado. También el Tribunal Supremo, en su Sentencia de 16 de enero de 1993, ha estimado la necesidad de que dichos órganos consultivos sean homologables al Consejo de Estado.

Desde diversos sectores de la doctrina se ha criticado la proliferación de Consejos Consultivos, al dudar de su capacidad para ejercer la función que, en exclusiva, ha venido ofreciendo el Consejo de Estado. Otros autores, por el contrario, han aplaudido la creación por las Comunidades Autónomas de órganos consultivos propios.

En mi opinión, y salvo alguna excepción a la que más adelante me referiré, los Consejos autonómicos cumplen esa condición de identidad de funciones y similares características a las del Consejo de Estado que postulaban nuestros Tribunales Constitucional y Supremo. Se puede afirmar que se trata de Instituciones que ejercen sus funciones con autonomía orgánica y funcional, y que no forman parte de la Administración activa ni se hallan integrados en Departamento gubernamental alguno, lo que unido a la cualificación técnica de sus miembros garantiza la objetividad e independencia en el ejercicio de sus funciones. El balance de estos últimos años creo que merece una calis

nomas. Pero se aprovechó la reforma para perfeccionar el sistema de autogobierno. En algunos Estatutos se incluyó la mención a instituciones ya constituidas o cuya creación se pretendia. Tal ocurrió en relación con los Consejos Consultivos autonómicos, en Baleares, Asturias o Castilla-La Mancha, dándole una nueva configuración en Canarias. 
ficación positiva para el ejercicio de la función consultiva por los correspondientes órganos autonómicos, que es satisfactoria y va adquiriendo, progresivamente, prestigio y utilidad.

La tipología de los Consejos autonómicos es, no obstante, variada, pese a compartir el común denominador como se ha expuesto, de una independencia del Ejecutivo, al tener garantizadas legalmente su autonomía orgánica y funcional. También gozan de potestad de autoorganización interna - que se traduce en la facultad de elaborar su propio Reglamento-, y de autonomía presupuestaria - confeccionan su propio Presupuesto que se integra en los de la Comunidad Autónoma-. Se configuran como Órganos Supremos del Gobierno respectivo y de su Administración, aunque también dictaminan en relación con las consultas que, preceptivamente, deben formularle las Corporaciones Locales, las Universidades, y demás Corporaciones y Entidades Públicas no integradas en la Administración autonómica.

La denominación de los órganos consultivos autonómicos es variada, aún cuando suele contener la calificación de «consultivo». En la mayor parte de la Comunidades Autónomas se denominan "Consejo Consultivon: Cataluña, Canarias, Andalucía, Galicia, Asturias ${ }^{20}$, La Rioja, Extremadura, Castilla-La Mancha, Castilla y León, e Islas Baleares; en la Comunidad Valenciana y en Cantabria, "Consejo Jurídico Consultivo"; en la Región de Murcia, "Consejo Jurídico"; en Navarra, simplemente "Consejo de Navarra"; y en Aragón, País Vasco y Cataluña21, "Comisión Jurídica Asesora".

Su composición y el estatuto de sus miembros es otra circunstancia a tener en cuenta a efectos de constatar la independencia de criterio de tales órganos, y de verificar si se ajustan en su configuración, conforme a los condicionantes apuntados por los Tribunales Constitucional y Supremo.

Están integrados, por regla general, por juristas de reconocida competencia a quienes se exige un tiempo mínimo de ejercicio de su profesión (entre siete y quince años), o por expertos en asuntos de Estado o autonómicos. De esta manera, se posibilita que formen par-

20 Su Estatuto de autonomía lo integra entre los "órganos auxiliares del Principado de Asturias». Vid. Art. 35 quarter.

21 Como es sabido, la función consultiva en Cataluña se ejerce tanto por el Consejo Consultivo como por la Comisión Jurídico Asesora, teniendo repartidas las competencias correspondientes. 
te de órganos que dictaminan en estrictos términos de legalidad, personas ajenas al mundo del Derecho. Tal ocurre, por ejemplo, en el Consejo Jurídico Consultivo de la Comunidad Valenciana, o en otros Consejos que cuentan con miembros natos (Extremadura, Castilla-La Mancha o Castilla y León).

Téngase en cuenta que, por lo general, los órganos consultivos autonómicos, contrariamente a lo que ocurre en el Consejo de Estado, no pueden pronunciarse, en ejercicio de sus funciones, sobre aspectos de oportunidad y conveniencia, a no ser que les sea expresamente pedido. Curiosamente, la Comisión Jurídica Asesora del Gobierno Vasco, si que puede valorar, también desde la perspectiva del interés general, los aspectos de oportunidad y conveniencia "cuando así lo exija la índole del asunto, o cuando lo solicite la autoridad consultan$t e{ }^{22}$.

Desde el punto de vista de su composición, observamos que hay varios modelos de órganos consultivos.

Dejando aparte el caso del Consejo de Estado, con tres tipos de Consejeros, (los permanentes, los electivos y los natos), la mayor parte de los Consejos Consultivos autonómicos están integrados por juristas elegidos bien por el Gobierno, bien parte de ellos por el Gobierno Y parte por el Parlamento.

Además, en cinco Consejos Consultivos (Andalucía, Castilla-La Mancha, Extremadura, Comunidad Valenciana y Castilla-León) se integran miembros natos (ex-Presidentes de la Comunidad y otros ex-altos cargos, por regla general, o en Andalucía, el Fiscal Jefe del Tribunal Superior de Justicia, el Jefe del Gabinete Jurídico o un representante de los Colegios de Abogados).

El mandato de los miembros de los órganos consultivos también varía en las distintas Comunidades Autónomas. Dejando aparte el régimen especial de los Consejeros natos a que se ha hecho referencia, el mandato se extiende desde 2 años en la Comisión Jurídica Asesora de Cataluña, hasta 6 años en Castilla y León, Navarra o Murcia, pasando por 3 años en la Comisión Jurídico Asesora de Aragón; 4 años en Baleares, Canarias o Galicia; y 5 años en Castilla-La Mancha, Extremadura y Comunidad Valenciana.

Al respecto conviene precisar que no me parece óptimo un mandato excesivamente corto, pues la estabilidad es garantía de indepen- 
dencia. Quizás por ello, incluso es oportuno que el mandato del Consejo difiera del de la Legislatura, lo que suele conseguirse, por otra parte, cuando una vez constituidos los órganos consultivos se van renovando con arreglo a sus respectivas previsiones legales. No hace falta señalar que quizás el carácter vitalicio de los Consejeros de Estado los dota de una estabilidad e independencia necesarias en este tipo de Instituciones; opción que, curiosamente, no ha sido seguida para configurar ninguno de los Consejos Consultivos autonómicos ${ }^{23}$. Ello no obstante no parece muy conveniente el carácter vitalicio de los Consejeros Permanentes de Estado, sin límite de edad. Al respecto hay que recordar que en 1968 se estableció, como edad máxima para el desempeño del cargo de Consejero de Estado, la de 75 años ${ }^{24}$, criterio que no siguió la vigente Ley Orgánica 3/1980. En la actualidad sólo en Extremadura está establecido un límite de edad -72 años -, para poder ostentar el cargo de Consejero electivo o permanente ${ }^{25}$.

Parece lógico que se fije un límite de edad habida cuenta la importante función que deben ejercer los miembros de los Consejos Consultivos y la dedicación que a ella deben prestar y considerando que tal límite no se compadece con la independencia y estabilidad de que deben estar revestidos. Es prácticamente común a todos los Consejos que sus miembros sean inamovibles durante su mandato.

También el estatuto de los miembros de los órganos consultivos ofrece dos modelos: el de dedicación exclusiva, sólo compatible con las funciones universitarias, docente e investigadora (como es el caso de la Comunidad Valenciana, Galicia, Canarias, Consell Consultiu de Cataluña o Castilla-León); y el de la compatibilidad con el ejercicio de

23 Martínez Sospedra, en referencia al Consejo Jurídico Consultivo de la Comunidad Valenciana, opina recomendable introducir un número de Consejeros permanentes a imagen y semejanza de los previstos en los arts. 7 y 11 de la Ley Orgánica del Consejo de Estado. Vid. "Las Institucions polítiques de la Comunitat Valencianan en la obra colectiva La societat valenciana: estructura social e institucional, Ed. Bromera, Valencia, 2000, pág. 455.

BlanOUER CRIADO estima, que la garantía institucional que protege a los órganos que ejercen la función consultiva no tolera que el miembro de ese órgano sea nombrado por un breve espacio de tiempo, máxime cuando puede ser renovado en su cargo. Por ello sugiere la conveniencia de un mandato de, por ejemplo siete años, y sin posibilidad de renovación. De esta forma se preservaría tanto la independencia como su apariencia. Vid. en Consejo de Estado y autonomias, Tecnos, 1994, págs. 125-125.

24 Ley 32/68, de 27 de julio, Artículo Único.

25 Art. 5.6 de la Ley 16/2001, de 14 de diciembre, del Consejo Consultivo de Extremadura. 
profesiones colegiadas y otro tipo de actividades profesionales (caso de la Comisión Jurídica Asesora de Cataluña, Illes Balears, Navarra o Andalucía).

La bondad o no de uno u otro modelo va a depender, fundamentalmente, del número de miembros con que cuenta el órgano y del trabajo a que tiene que hacer frente. Desde mi experiencia en el Consejo Jurídico Consultivo de la Comunidad Valenciana, opino que tratándose de un órgano tan reducido - con sólo cuatro Consejeros electivos-26, difícilmente se podría ejercer debidamente la función consultiva sin exclusiva dedicación, cuando se reciben anualmente en torno a las seiscientas consultas.

Hay que indicar que todos los órganos consultivos cuentan con un Secretario General, Consejero-Secretario o Letrado-Secretario General, que por lo regular, y a menos que sea miembro del Consejo, asiste a éste con voz pero sin voto, y desempeña importantes funciones en orden a la coordinación de los Letrados y de los servicios administrativos del órgano.

Los Letrados son, precisamente, un elemento personal de indudable relevancia. En algunas Comunidades Autónomas como Galicia, Canarias o la Comunidad Valenciana se ha creado un específico cuerpo de Letrados, aunque no en todos los supuestos se ha celebrado oposición para acceder al mismo. En otros casos, la función letrada es ejercida por funcionarios de la respectiva Administración autonómica.

Por último, y en relación con las competencias hay que indicar que, como es obvio han de estar referidas a las asumidas por las respectivas Comunidades Autónomas, o a las previsiones de la normativa básica estatal. A estas últimas responde la preceptiva consulta en relación con los expedientes instruidos por las Administraciones en materia de responsabilidad patrimonial; de revisión de oficio de actos nulos; de recursos extraordinarios de revisión; o de determinados supuestos de contratación pública.

Común a todos los Consejos es su dictamen preceptivo en relación con los proyectos de reglamento o disposiciones de carácter gene-

26 En su Memoria correspondiente a 2001 el Consejo Jurídico Consultivo de la Comunidad Valenciana se hacía eco de su composición excesivamente exigua para seguir manteniendo la puntualidad $y$ celeridad con la que viene despachando los asuntos. 
ral que se dicten en ejecución de leyes y sus modificaciones, tal cual ocurre con el Consejo de Estado.

Pero además, muchos de los Consejos autonómicos también tienen reconocida la competencia de dictaminar los Anteproyectos de Ley elaborados por sus respectivos Gobiernos. Tal ocurre en Canarias, Castilla-León, Extremadura, Illes Balears, Galicia, Comunidad Valenciana y Andalucía ${ }^{27}$. Igualmente deben dictaminar los proyectos de legislación delegada; los convenios y acuerdos de cooperación con otras Comunidades Autónomas; los conflictos de atribuciones entre los distintos departamentos de sus respectivos gobiernos, etc.

Ello pone de manifiesto que nada impide que junto a los supuestos establecidos en la legislación básica estatal, como garantía para el administrado, se establezcan otros específicos que cada Comunidad Autónoma considere convenientes.

Pero no podemos olvidar, además, que junto a los asuntos de preceptiva consulta, los Gobiernos autónomos pueden someter a consideración de los órganos Consultivos cualquier cuestión, con carácter facultativo, para que se dictamine en términos de estricta legalidad.

\section{EL EXTRAÑo MODELO DEL PAÍS VASCO}

Como ya he indicado, el Consejo de Estado es el modelo a seguir por las Comunidades Autónomas a la hora de crear sus órganos consultivos. Esa caracterización es necesaria para que la función consultiva sea ejercida de forma objetiva e independiente.

Como ya he tenido ocasión de señalar en otro momento ${ }^{28}$, en el País Vasco la configuración de su Comisión Jurídica Asesora es bien distinta. En primer lugar, ha sido creada por Decreto 187/1999 de su Gobierno, careciendo, por tanto, de garantía estatutaria o legal de la que gozan los demás órganos consultivos autonómicos. En segundo lugar, se halla integrada en la Secretaría General de Régimen Jurídico del Gobierno Vasco, como "órgano colegiado superior consultivo de la Administración de la Comunidad Autónoma de Euskadi», aunque

27 En los casos de la Comunidad Valenciana y Canarias, con excepción del Anteproyecto de Ley de Presupuestos.

28 Vid. V. GARRIDO MAYOL, "La función consultiva en la Comunidad de Madrid», cit. págs. 579 y ss. 
"actúa con independencia jerárquica, orgánica y funcional, con respecto a los órganos de la Administración activan, lo que es difícil de entender a la luz de las disposiciones básicas que configuran el régimen jurídico de las Administraciones Públicas, contenidas en la Ley 30/1992, de 26 de noviembre.

Pero es que, además, son miembros natos de la Comisión, el Secretario General de Régimen Jurídico del Gobierno Vasco y el Director General de Desarrollo Legislativo y Control Normativo. El primero ostenta la Presidencia de la Comisión, y el segundo, la Vicepresidencia. Los seis vocales de la Comisión son nombrados mediante Orden por la Vicepresidencia del Gobierno, de entre Letrados adscritos a la Secretaría General de Régimen Jurídico. Todos ellos son nombrados por un periodo de tres años $y$ como causas de cese sólo se establecen la expiración del mandato y el hecho de dejar de ocupar el puesto de Letrado en la Secretaría General de Régimen Jurídico, olvidando que tanto el Presidente de la Comisión, como su Vicepresidente, pierden su condición de tales si son cesados como Secretario General y Director General respectivamente, en su condición de altos cargos del Gobierno Vasco.

Además, el Secretario General de Régimen Jurídico-Presidente de la Comisión Jurídico Asesora, conserva el ejercicio de su función consultiva como Secretario General ${ }^{29}$. De tal modo que es posible que como Secretario General tenga que informar asuntos que, posteriormente sean sometidos a consulta de la Comisión Jurídica Asesora. Como es posible que los Vocales de la Comisión, como Letrados del Gobierno, también hayan intervenido, previamente a la actuación de la Comisión, en la instrucción de los procedimiento que, luego, son sometidos a dictamen de aquella.

Evidentemente, a mi juicio, no es éste el modelo de órgano consultivo al que se han referido tanto el Tribunal Constitucional como el Tribunal Supremo, como sustitutivos del Consejo de Estado en las respectivas Comunidades Autónomas. Dice la Parte Expositiva del Decreto que crea la Comisión Jurídica Asesora del Gobierno Vasco, que "Entre las diversas fórmulas mediante las que puede organizarse la función consultiva, este Gobierno ha considerado desde el principio que la más idónea es su integración en los servicios jurídicos de cada Administración, si bien cuidando de salvaguardar la objetividad e imparcialidad que requiere dicha función". A tal efecto invoca la Ley 
Estatal 4/1999, de 13 de enero, de modificación de la Ley 30/1992, de 26 de noviembre, que introdujo en ésta una Disposición Adicional, la Decimoséptima, en virtud de la cual "La Administración consultiva podrá articularse mediante órganos específicos dotados de autonomía orgánica y funcional con respecto a la Administración activa, o a través de los servicios jurídicos de ésta última». Disposición que, en mi opinión, no respeta la jurisprudencia del Tribunal Constitucional contenida esencialmente en su citada Sentencia 204/1992, y la del Tribunal Supremo, según sus Sentencias de 24 de noviembre de 1989 (Sala Especial de Revisión), y de 16 de enero de 1993.

Quizás hay que pensar que el Gobierno Vasco, más que acogerse a lo que la Ley 30/1992, propició la introducción de la nueva Disposición Adicional Decimoséptima, teniendo en cuenta su negativa a crear un órgano consultivo de características similares a las del Consejo de Estado o de recabar el dictamen del Alto Cuerpo Consultivo, en asuntos de preceptiva consulta. Téngase en cuenta que es reiterada la jurisprudencia del Tribunal Supremo - que por unánime y constante no precisa de concreta cita-, en el sentido de que los actos administrativos dictados sin la intervención preceptiva del Consejo de Estado o del órgano consultivo autonómico, alli donde exista, son nulos de pleno derecho, al haberse producido con omisión de una garantía esencial del procedimiento.

Es éste otro de los rasgos característicos de los órganos consultivos: la omisión de su dictamen preceptivo constituye un vicio de nulidad de la disposición aprobada o de la resolución dictada.

Por ello, sin dudar en absoluto de la competencia y profesionalidad de quienes integran la Comisión Jurídica Asesora del Gobierno Vasco, estimo que este órgano consultivo se aparta del modelo común al resto de Comunidades Autónomas y del que constituye el Consejo de Estado.

Como advierte Lavilla Alsina tras analizar la jurisprudencia de los Tribunales Constitucional y Supremo, queda pendiente de futuras decisiones jurisdiccionales la apreciación de si la exigencia legal de que en un procedimiento medie un acto consultivo, se satisface con la intervención del correspondiente órgano consultivo; sobre si la homologación y equivalencia con el Consejo de Estado se da o no efectivamente $^{30}$.

30 L. Lavilla Alsina, La Administración consultiva del Estado, cit. pág. 473. 


\section{RECAPITULACIÓN}

En estos veinticinco años de vigencia de la Constitución de 1978 la función consultiva ha experimentado una notable transformación. De un lado, se ha consolidado el Consejo de Estado, aun con una configuración similar a la diseñada en 1944, como Alto Cuerpo Consultivo del Gobierno de la Nación. Por otra, se han creado Consejos Consultivos en la práctica totalidad de la Comunidades Autónomas, que sustituyen al Consejo de Estado en sus respectivos ámbitos territoriales y que están prestando una útil colaboración como órganos independientes a la autoridad consultante.

En definitiva, se ha reforzado la garantía de defensa del interés público y del ciudadano, contribuyendo, de este modo, a consolidar lo que debe ser un Estado social y democrático de Derecho que nuestra Constitución propugna. 